\title{
A case series of etomidate use in ACTH ectopic syndrome in endocrine neoplasms
}

\author{
Georgios Boutzios, Georgios Nikolopoulos, Krystallenia Alexandraki, Maria \\ Kaltsatou, Maria Chrysochoou, Marina Tsoli, Gregory Kaltsas
}

Endocrine Unit, Department of Pathophysiology, University of Athens, Medical School,
Laiko Hospital, Athens, Greece

\section{Aim of Study}

Describe etomidate use in cases of uncontrolled hypercortisolemia due to ACTH ectopic syndrome in endocrine neoplasms

\section{Introduction}

Etomidate is an imidazole derivative which inhibits several enzymatic steps (11ß-hydroxylasey, 17 $\beta$-hydroxylase, 17,20-lyase, cholesterol side-chain cleavage). Intravenous etomidate at sub-anaesthetic doses remains an important option when intravenous administration is required for rapid treatment of severely ill patients with hypercortisolemia (Cushing's syndrome, CS) and is almost always very effective. A review of 18 studies, 43 cases (age 6-

73 years); January 1946 to April 2012
Etomidate administration 5hrs to 5.5
months

\section{Cases Illustration}

Case 1: A 49-year-old woman

- Left adrenocortical carcinoma (ACC) [T4N1M1, stage IV ENSAT 2008,Ki-67: 15\%l and CS.

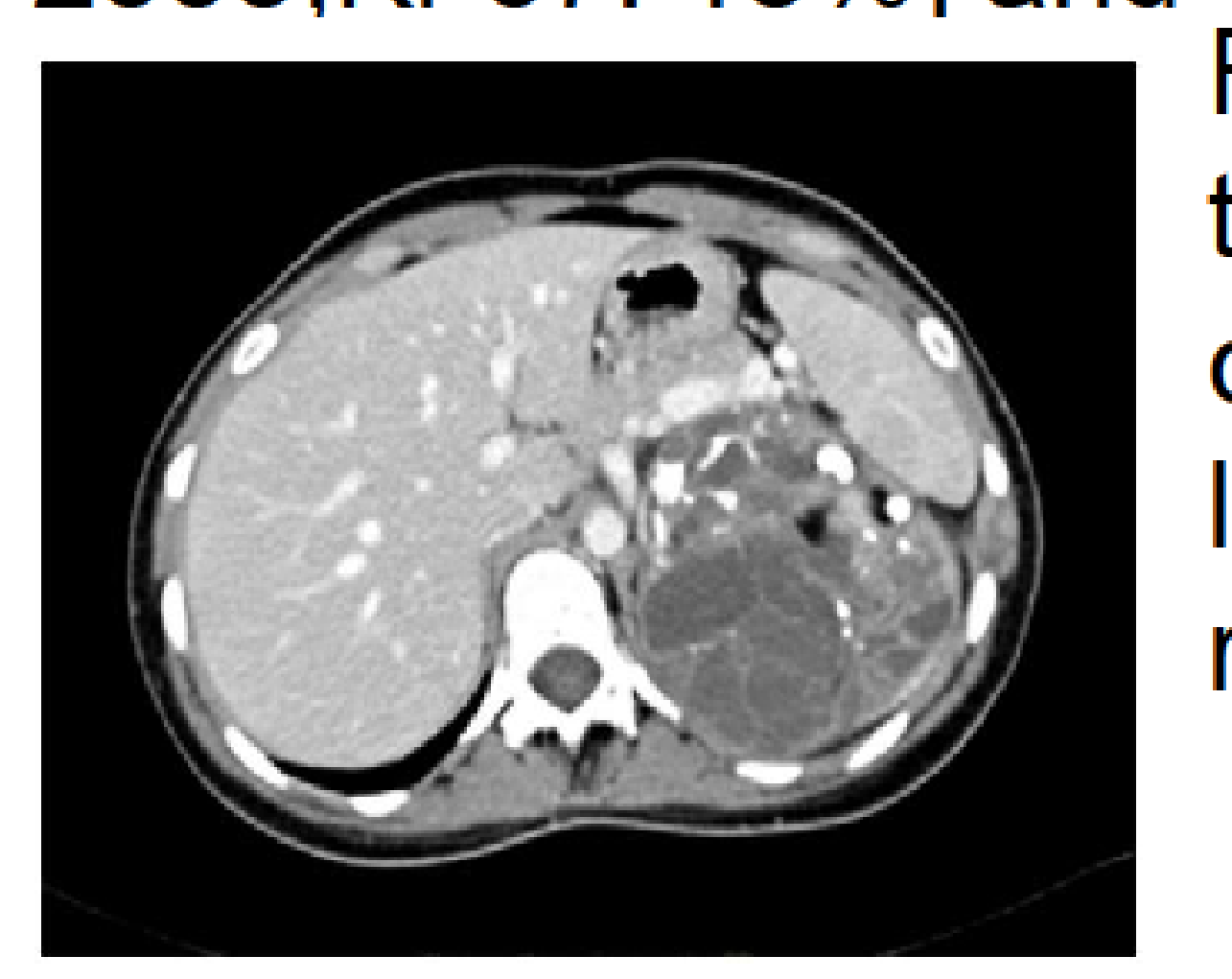

Recurrence 6 months after surgical removal of the primary tumor while she had received chemotherapy and adrenolytic therapy: new liver metastases and cortisol values with recurrence of CS

She received $2.4 \mathrm{mg} / \mathrm{h}$ of etomidate intravenously for 7 days

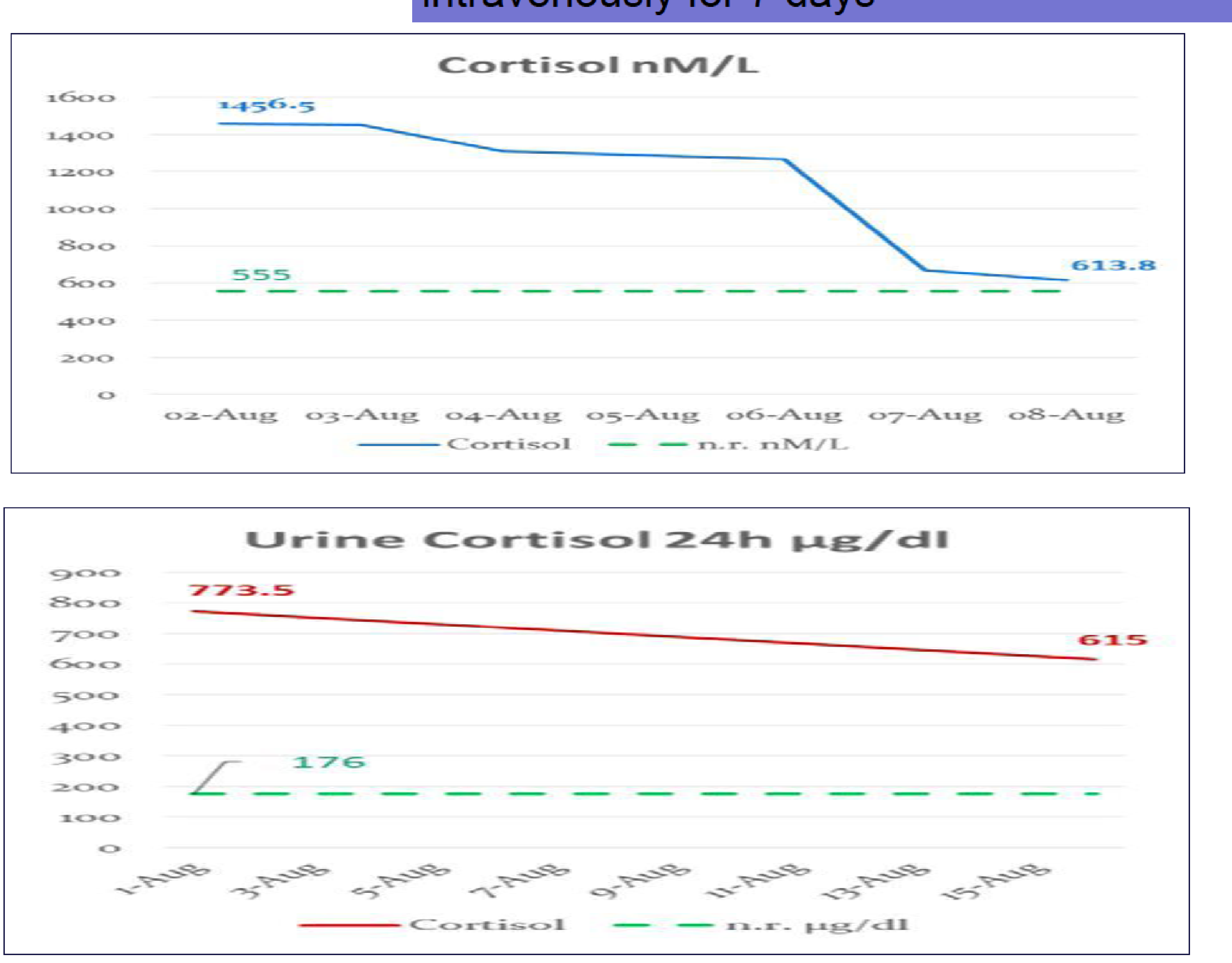

The patient died because of sepsis one month later

\section{Cases Illustration}

Case 2: A 72-year-old man - Atypical lung neuroendocrine neoplasm (NEN) (T1aNxMx, Ki-67: 4-7\%) and ectopic secretion of ACTH (ACTH: $78.7 \mathrm{pg} / \mathrm{ml}$ )

-Surgical removal of the primary tumor followed by chemotherapy [CisplatinEtoposside; TemozolomideCapecitabine]

somatostatin analogs

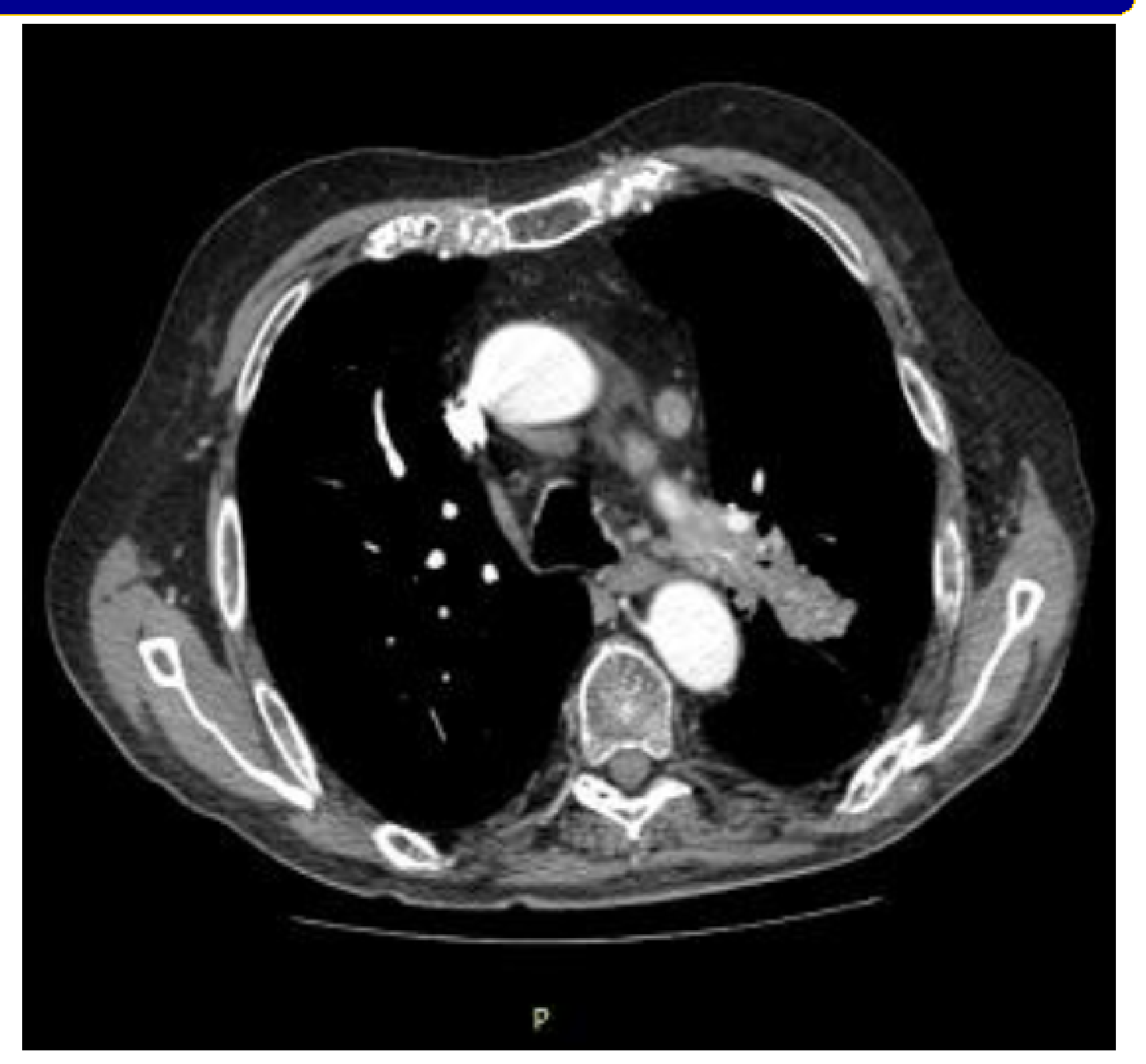

- Disease recurrence 6 years later

-Metyrapone and ketoconazole treatment: no adequate control of CS (pre-treatment-UFC: $709 \mathrm{mg} / 24 \mathrm{~h}$, post-treatment-UFC: $416 \mathrm{mg} / 24 \mathrm{~h}$ )

Etomidate was administered at a dose of $3-3.3 \mathrm{mg} / \mathrm{h}$ intravenously

\begin{tabular}{|l|l|l|}
\hline & Pre-treatment & Post-treatment \\
\hline Cortisol levels $(6.2-19.4 \mu \mathrm{g} / \mathrm{dl})$ & 44 & 23
\end{tabular}

Bilateral adrenalectomy was performed and
hypercortisolemia was controlled

Case 3: A 51-year-old woman
-Medullary thyroid carcinoma (T3NxM1, stage IV), liver metastases and ectopic secretion of ACTH (ACTH: 153pg/ml, F: 74 $\mu \mathrm{g} / \mathrm{dl})$
Thyroidectomy without resolution of CS

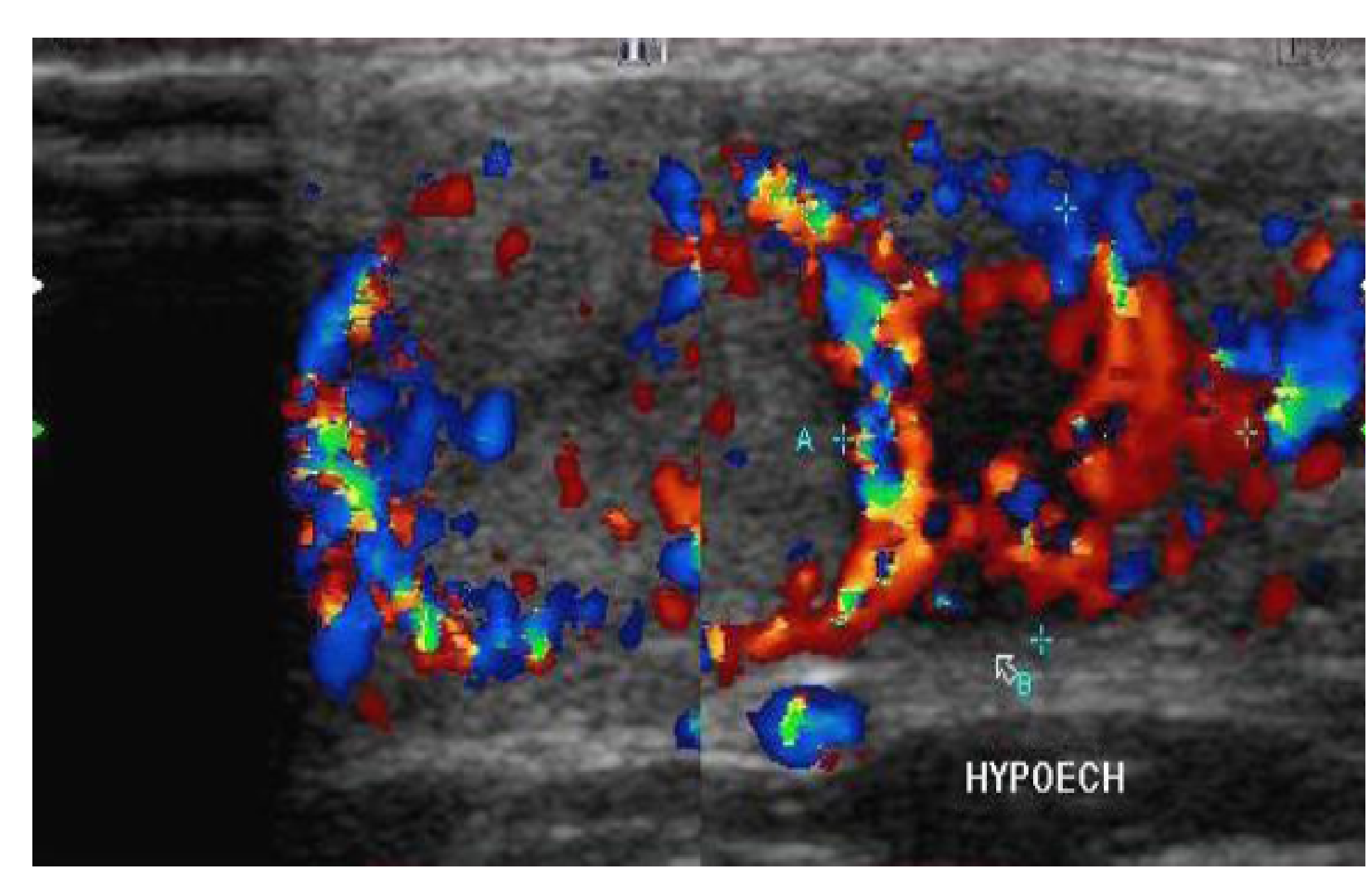

- Etomidate intravenously at a dose of $2.6 \mathrm{mg} / \mathrm{h}$ with a decrease in cortisol levels (pre-treatment-F: $273.8 \mu \mathrm{g} / \mathrm{dl}$, post-treatment-F: $79.2 \mu \mathrm{g} / \mathrm{dl})$.

The patient died because of a septic shock two days later.

\section{Summary of patients outcome}

Hypercortisolemia controlled in all patients

2 out of 3 patients died because of sepsis before their definitive treatment with bilateral adrenalectomy

\section{Conclusions}

Etomidate may be used as first-line treatment in severely ill patients with CS.

However, it needs to be very carefully monitored, because of sedation that may be apparent in higher doses, and adjustments should be made with regards to renal failure and stressed situations such as sepsis.

References

- Gross et al. Neurosurg Focus. 2007;23:E10

- Preda et al. European Journal of Endocrinology (2012), 167 137-143 